\title{
Cells, growth factors and bioactive surface properties in a mechanobiological model of implant healing
}

\author{
${ }^{1}$ G. Guérin, Msc. \\ ${ }^{1,2} \mathrm{D}$. Ambard, $\mathrm{PhD}$ \\ ${ }^{1}$ P. Swider, Ph.D.
}

\begin{abstract}
From:
1 - Biomechanics Group, IMFT UMR CNRS 5502, University of Toulouse - France 2 - LMGC UMR CNRS 5508, Montpellier - France
\end{abstract}

Keywords: implant fixation, mechanobiology, growth factor, osteoblast, transport in porous media, biomaterial

Word count: 3041

Corresponding author:

Professor Pascal Swider

Biomechanics Group, IMFT UMR CNRS 5502, Toulouse 3

CHU Purpan, Amphithéâtre Laporte

Place Dr Baylac,

31056 Toulouse cedex

FRANCE

Phone: int'1 33(5) 61497944

Fax: int'l 33(5) 61496745

Email: swider@cict.fr 


\begin{abstract}
Interface conditions are of prime importance for implant fixation in the early post-operative period and modelling of specific biochemical interactions at implant surface is still missing. We hypothesized that updating osteoblast adhesion properties and growth factor source in an active zone located at the implant surface was relevant to model biochemical interactions of implant with its environment. We proposed an innovative set of diffusive-convective-reactive equations which relevant parameters were the cell decay factor, the cell motility, and the growth factor balance.

Initial comparison with histomorphometic results from a stable $P M M A$ canine implant model provided an encouraging base to implement a numerical sensitivity analysis to evaluate the role of three types of bioactive surfaces: acid-etched titanium, coarse grit blasted acidetched titanium and coarse grit blasted acid-etched titanium with $R G D S$ peptide. We found that cell diffusion decrease (acid-etched $+R G D S$ peptide vs. PMMA), and increase of local growth factor fraction (PMMA vs. acid-etched $+R G D S$ peptide), significantly improved the amount of mineralized tissue on the implant surface. When the variation of structural fraction to cell motility and growth factor synthesis was investigated, an envelope pattern with an optimum was obtained but this could be exceeded for strong surface modifications and/or for high growth factor concentrations. The model also confirmed that implant bioactive properties should play a limited role to reduce heterogeneity of new-formed tissue. In conclusion, we suggested that our innovative theoretical approach was relevant to investigate implant fixation and could potentially help in reduction of implant revision.
\end{abstract}

Keywords: implant fixation, mechanobiology, growth factor, osteoblast, transport in porous media 


\section{Introduction}

Conditions favoring periprosthetic tissue healing in the early post-operative period is an open clinical problem. Low performance of implant fixation is generally associated with a low mineralization or a heterogeneous ossification of the new-formed tissue. Three parameters have a significant influence on this process: the surgical technique (Hahn et al. 1988; Morshed et al. 2007), the post-operative mechanical stimuli and the biochemical factors amongst which physico-chemical properties of implant surface are essential (Anderson et al 2001; Colnot et al.2007; Belmont et al. 2008; Kromer et al. 2008). Clinical studies and animal studies investigated the role of implant surface properties in osteointegration (Overgaard, 2000; Svehla et al., 2000; Buser et al., 2007; Duyck et al., 2007; Qu et al., 2007; Schwartz et al., 2007).

Cell adhesion involves short-term events such as physicochemical linkages between cells and substrates and long-term events leading to the regulation of cell expression involving extracellular proteins, cell membrane proteins and cytoskeleton proteins (Anselme, 2000). Cytoskeleton proteins mediate interaction between cell membrane proteins and nucleus via actin filaments, and regulate gene expression (Sinha and Tuan, 1996). Extracellular matrix proteins have adhesion properties due to RGD sequence (arginine-glycine-aspartate) specific to fixation of cell membrane receptors (Grzesik and Robey, 1994). Integrin type receptors of cell membrane proteins induce cell-substrate adhesion establishing focal contacts. Cell migration on substrate can be explained by adhesive interaction involving integrins that locally generate cell traction (Wu et al., 1995). In case of implants, material properties and surface modification clearly affect cell adhesion and proliferation, and growth factors production (Kieswetter et al., 1996; Kilpadi et al., 2001; Colnot et al., 2007; Popat et al., 2007; Anderson, 2001; Raush-fan et al., 2008). It is observed that sensitivity to surface topology is significant (Pessková et al., 2007; Neidlinger-Wilke et al., 1994; Fermor et al., 1998) and generally, osteoblastic proliferation decreases when surface roughness increases (Martin et al., 1995; Rosa and Beloti, 2003; Mustafa et al., 2001).

Cells produce a significant range of growth factors amongst with TGF- $\beta 1$ is the major regulator of bone formation. It involves unique mitogenic action on osteoblasts and it shows ability to stimulate matrix formation via autocrine, paracrine and endocrine modes (Roberts, 2000 ). Here also, substrate properties modify the amount of TGF- $\beta 1$ produced by osteoblasts. It is shown that the production rate is higher for rough surface (Schwartz et al., 1997) or in the presence of oxide (Albrektsson et al., 1983), while the presence of metal particles is affecting TGF- $\beta 1$ synthesis (Wang et al., 1997).

Relevant biomathematical models of migration and differentiation have been proposed in skin and fracture healing, angiogenesis or bioreactors (Tracqui, 1999; Tranqui et al., 2000; Bailon-Plaza and Van Der Meulen, 2001; Sengers et al., 2007). Most computational models of implant fixation were initially based on pure mechanical approaches (Ramamurti et al., 1997; Prendergast, 1997, Viceconti et al., 2000; Mesfar et al., 2003; Simon et al.; 2003) and more recently, biochemical aspects have been added (Fernandes et al., 2002, Puthumanapully et al., 2008, Geris et al. 2008a \& b; Checa and Prendergast, 2009). Reliability of numerical predictions has rarely been correlated to in-vivo or ex-vivo data. We proposed an original framework to model implant healing unifying mechanical and biomathematical approaches while considering the biological tissue as a multiphasic convective-diffusive-reactive medium (Ambard et al., 2004a\&b, 2005a\&b, 2006, 2007, 2009). The reliability of our theoretical approach was supported by ex-vivo data from canine implant models (Søballe et al., 1992; Vestermark et al. 2004).

It appears that interface conditions are of prime importance for bone apposition and implant anchorage. However, modelling of specific biochemical interactions at implant surface is still 
missing and in our knowledge, no predictive model explicitly involved the biochemical interactions between the implant surface properties and the surrounding biological tissue. We hypothesized that local modification of cell adhesion properties and growth factor source was a way to model interactions between the implant and its environment. To proceed, we firstly proposed a set of new mechanobiological governing equations. Second, we evaluated the model relevance against histologic data from a PMMA canine implant model (Vestermark et al. 2004). Around this reference solution, we thirdly implemented a numerical sensitivity analysis to quantified the potential role of three types of modified surfaces: acid-etched titanium, coarse grit blasted acid-etched titanium and coarse grit blasted acid-etched titanium with $R G D S$ peptide.

\section{Material \& Methods}

\subsection{Governing equations:}

The association of porous media mechanics to biomathematics allowed the diffusiveconvective-reactive governing equations (1) to be derived. Non-linear coefficients $L, C, D, \Omega$ described the local variation, the convection, the diffusion, and the source terms. Output measure $u$ was the structural or mineralized fraction $\phi_{s}$, the fluid fraction $\phi_{f}$, the growth factor concentration $C_{g}(T G F-\beta 1)$ and the osteoblast concentration $C_{o}$. At the scale of tissue volume unit, volumes of cell phase and growth factor phase were neglected compare to the volume of structural and fluid phases. Fluid fraction $\phi_{f}$ also described the porosity of the newly formed tissue since $\phi_{s}+\phi_{f}=1$. Phases were incompressible with no substrate strain in quasi-static isothermal evolving. Structural porosity, fluid flow and growth factors conditioned the cellular behavior: proliferation, chemotactic and haptotactic migrations of cells, and mineral fraction apposition.

$L \frac{\partial u}{\partial t}=D \Delta u-C \nabla u+\Omega$

The evolving of osteoblast concentration was described by cell conservative equation (2) where diffusion coefficient $D_{o}$ and convection coefficients $\chi_{o}$ and $h_{o}$, respectively allowed modelling random cell migration (Lauffenburger et al., 1983; Dee et al., 1999), chemotactic active migration and haptotactic active migration. Chemotactic flux of cells was dependant upon the growth factor gradient $\nabla C_{g}$ whereas haptotactic flux was conditioned by the gradient of structural matrix $\nabla \phi_{s}$. The cell source $\Omega_{o}$ represented the proliferation process with the logistic law (3) where $\alpha_{o}$ and $C_{o m}$ respectively were the rate of cell divisions and the proliferation threshold. The role of available growth factors in cell proliferation was specifically taken into account using algebraic difference between the current concentration $C_{g}$ and the physiological threshold $C_{g p}$ (Centrella et al., 1994; Alliston and Derynck, 2000).

$\frac{\partial\left(\phi_{f} C_{o}\right)}{\partial t}=D_{o} \nabla\left(\phi_{f} C_{o}\right)-\chi_{o} \nabla\left(\phi_{f} C_{g}\right)-h_{o} \phi_{f} C_{o} \nabla \phi_{s}+\Omega_{o}$

$\Omega_{o}=\alpha_{o} \phi_{f}{ }^{3} C_{o}\left(C_{o m}-C_{o}\right) \times\left(C_{g}-C_{g p}\right)$

The growth factor concentration per tissue volume unit was expressed by conservative equation (4). Replacing the initial diffusion coefficient $D_{g}$ by the effective diffusion coefficient (Maxwell, 1881; Neale and Nader, 1973) allowed modelling local retention of growth factors in the primary gap due to surgery. At Darcy scale, fluid flux relative to structural phase was relied to the pore pressure $p$ and permeability $\kappa_{s}$ dependant from $\phi_{f}$ (Cowin, 2001).

$\frac{\partial\left(\phi_{f} C_{g}\right)}{\partial t}=D_{g e} \nabla\left(\phi_{f} C_{g}\right)-\phi_{f} C_{g} \kappa_{s} \nabla p+\Omega_{g} \quad$ with $\quad D_{g e}=2 \phi_{f} D_{g}\left(3-\phi_{f}\right)^{-1}$ 
Equation (5) governed the growth factor source $\Omega_{g}$. The endocrine mode was governed by the growth factor concentration imposed as initial condition in the model. To account modes of production, equation (5) involved fluid fraction (or tissue porosity) $\phi_{f}$, osteoblast concentration $C_{o}$, and growth factor concentrations $\left(C_{g}, C_{g p}\right)$. Coefficient $\alpha_{g}$ was the coefficient of growth factor synthesis and $d_{g}$ was the decay factor taking into account the consumption of growth factor due to osteoblast activity (Stein et al, 2000).

$\Omega_{g}=\alpha_{g} \phi_{f} C_{o}-d_{g} \phi_{f}{ }^{2} C_{o} \times\left(C_{g}-C_{g p}\right)$

The synthesis of mineral matrix was modelled in equation (6) using the source $\Omega_{s}$ involving the synergetic action of osteoblast $C_{o}$ and growth factors $C_{g}$ (Meinel et al, 2003). It was promoted by the fluid fraction $\phi_{f}$ and the coefficient of matrix synthesis $\alpha_{s}$.

$\Omega_{s}=\alpha_{s} \phi_{f}{ }^{2} C_{o} \times\left(C_{g}-C_{g p}\right)$

\subsection{Active zone of implant}

The periprosthetic zone of interest was divided into three sub-domains as shown in Figure 1a. The peripheral domain was the host trabecular bone; the boundaries of intermediate domain were the implant surface and the drill hole. This corresponded to the immediate postoperative gap. We considered a third domain corresponding to the zone of influence of the implant or the active zone. This was a layer of a few microns thickness located at the implant surface, where implant bioactive properties modified the growth factor source and the cell flux. Cell adhesion was surface- dependant thanks to diffusion coefficient $D_{o}$ in equation (2). Low value of $D_{o}$ meant significant adhesive properties of the surface.

The local influence on growth factor phase was managed adapting conservative equations (5) and (6). First, the decay factor $d_{g}$, expressed by equation 7a, was obtained assuming a negligible production mode $\left(\alpha_{g}=0\right)$, a negligible pressure gradient $(\nabla p=0)$, and nil growth factor gradients $\left(\nabla C_{g}=0\right)$. Second, the synthesis factor $\alpha_{g}$ was calculated using equation (7b) with $d_{g}$ previously determined and according to the same assumptions in gradients.

$$
d_{g}=-\frac{\partial\left(C_{g}\right)}{\partial t}\left[\phi_{f} C_{o} \times\left(C_{g}-C_{g p}\right)\right]^{-1} \quad \text { (a) } \quad \alpha_{g}=\frac{1}{C_{o}}\left[\frac{\partial C_{g}}{\partial t}+d_{g} \phi_{f} C_{o} \times\left(C_{g}-C_{g p}\right)\right]
$$

Finally, the active zone was characterized by the cell diffusion coefficient (or motility) $D_{o}$, the synthesis coefficient $\alpha_{g}$ and the cellular decay factor $d_{g}$.

\subsection{Application to the experimental canine model and sensitivity analysis}

The reference implant was a PMMA stable canine implant previously evaluated in-vivo (Vestermark et al, 2004) (Fig.1b). Boundary conditions and peri-implant tissue formation showed a polar symmetry with a variable level of mineralization in the radial direction $r$. The set of governing equations previously presented was translated into a custom made axisymmetric finite element formulation. Nine nodes quadratic elements were used with structural fraction $\phi_{s}$, growth factor concentration $C_{g}$, osteoblast concentration $C_{o}$ and fluid pressure $p$ as nodal variables. The associated computational model was implemented with the Python programming language (Python Software Foundation $\left.{ }^{\circledR}\right)$ using Pysparse module to solve the spatio-temporal finite element matrix system.

The model is described in Figure 1c. The domain was radially defined by the implant radius $\left(r_{i}=3.25 \mathrm{~mm}\right)$, the drill-hole $\left(r_{d}=4.1 \mathrm{~mm}\right)$ and the surrounding trabecular bone $\left(r_{s}=7 \mathrm{~mm} \approx\right.$ $\left.2 \times r_{i}\right)$. We assumed a 15 microns thick layer for the active zone considering implant surface roughness comprises between 0 and 5 microns (Kim et al., 2006; Marinucci et al., 2007; Meirelles et al., 2007) and mean osteoblast size of 10 microns (Buser et al., 2004). The meshing was made of 201 nodes and 1206 DOF with steps evolving from 15 microns for the active zone, 60 microns for the intermediary zone and varying from 60 microns to 315 
microns up to the surrounding trabecular bone.

As boundary conditions, fluid flux, cell flux and growth factor flux were nil at boundaries of the investigated domain shown in Figure 1c; the porosity $\phi_{f}$ of the host trabecular bone was $50 \%$. As temporal initial conditions, osteoblast concentration of $1000 \mathrm{cell} / \mathrm{mm}^{3}$ was homogenously distributed into the surrounding bone and post-operative gap, and growth factor concentration of $0.15 \mathrm{ng} / \mathrm{mm}^{3}$ was homogenous into the gap. According to in-vivo experiment, the healing process was evaluated up to 8 weeks post-operatively. Model data are summarized in Table 1.

As shown previously, the implant active zone was characterized by the triplet $\left(D_{o}, d_{g}, \alpha_{g}\right)$. This triplet in its wholeness was unavailable in the literature, especially including our specific constraints: osteoblastic lineage, TGF- $\beta_{1}$ and orthopedic implant in-vivo. Only data coming from cell assays could be used. First, decay factor $d_{g}$ was obtained from equation (7a) using a finite difference scheme in time imposing a decay of 5\% each 100 minutes (Wakefield et al. 1990). This parameter was assumed intrinsic to the cell phase, and it was kept independent from the substrate because of a lack of available experimental data in the literature. Second, cell diffusion coefficient $D_{o}$ was extracted from (Dee et al.1999). Third, the synthesis coefficient $\alpha_{g}$ was obtained from equations (7a) and (7b) using a finite difference resolution in time and TGF- $\beta 1$ concentrations measured in presence of several types of substrates. PMMA, acid-etched titanium, coarse grit blasted acid-etched titanium, and coarse grit blasted acidetched titanium with $R G D S$ peptide (Raush-fan et al., 2008). According to in-vitro experiments, the structural fraction was nil $\left(\phi_{s}=0\right)$ inducing a porosity $\phi_{f}$ fixed to unity.

Since accessible by histomorphometry in case of $P M M A$ implant, the distribution pattern of structural (or mineralized) fraction $\phi_{s}$ was targeted to evaluate the reliability of the computational model. After this step, a numerical sensitivity analysis was conducted involving the surface-dependant doublet $\left(D_{o}, \alpha_{g}\right)$ in case of PMMA and surface-modified titanium substrates.

\section{Results}

Computations were established using a decay factor $d_{g}$ of $8.5 \times 10^{-11} \mathrm{~mm}^{3} /$ cell.s, obtained from the resolution of equation (7a). Because of lack of available data in literature, we assumed that $d_{g}$ was identical for the investigated bioactive surfaces, since intrinsic to the osteoblastic phase and established with the same growth factor concentration. However, parameters $\left(D_{o}, \alpha_{g}\right)$ obtained from equation $7 \mathrm{~b}$ were surface-dependant and summarized in Table 2.

The ex-vivo and computed radial distribution pattern of structural fraction $\phi_{s}$ with $P M M A$ implant were plotted in Figure 2. In digitized histological slices, the summation in concentric zones of structural fraction pixels was divided by the pixel overall summation of the zone of interest to derive the radial distribution of structural fraction. Mean value was established on a base of four slices. It can be observed in Figure 2 that magnitude and radial pattern were well predicted by the computational model.

Distribution pattern for the other three types of bioactive surfaces were also plotted in Figure 2. We observed significant differences since $\phi_{s}$ at the implant surface, increased from $59 \%$ for $P M M A$ to $87 \%$ for the coarse grit blasted acid-etched with $R G D S$ peptide. Differences were attenuated close from the drill hole and non-significant in the host bone whatever the implant constitutive material. We varied the active zone thickness (15 microns \pm $20 \%$ ) and it confirmed the local effect of this parameter.

The numerical sensitivity analysis plotted in Figure 3 first confirmed that the decrease of diffusion coefficient $D_{o}$ globally increased the structural fraction $\phi_{s}$ into the active zone. To go further, it appeared that the variation pattern of $\phi_{s}$ to doublet $\left(D_{o}, \alpha_{g}\right)$ could be described by a 
generic monotonic function increasing up to an optimum and then decreasing. This was clear for the acid-etched grit-blasted titanium with the optimum (point $A$ ) obtained for $\alpha_{g} \approx 16 \times 10^{-}$

$11 \mathrm{ng} / \mathrm{cell} . \mathrm{s}$, and for the acid-etched grit-blasted titanium $+R G D S$ which optimum was obtained for $\alpha_{g} \approx 38 \times 10^{-11} \mathrm{ng} / \mathrm{cell} . \mathrm{s}$ (point $B$ ). For the acid-etched titanium, the optimum was not reached for the range of $\alpha_{g}$, and or the $P M M A$, the structural fraction was not influenced by $\alpha_{g}$. We evaluated a theoretical active surface with a particularly low diffusion coefficient $D_{o}$ of $1.251 .25 \times 10^{-7} \mathrm{~mm}^{2} / \mathrm{s}$, and we obtained a constant decrease of structural fraction; the optimum could potentially be reached for lower values of $\alpha_{g}$.

\section{Discussion}

Periprosthetic healing is an endochondral process involving complex biological events, and how biological medium reacts with the implant was underlying our approach. The mechanical aspect belonged to the domain of reactive transport in porous medium. We proposed an original set of diffusive-convective-reactive governing equations to investigate in time and space, the role of surface bioactive properties on cell flux, growth factor balance and finally structural (or mineral) fraction formation.

We proposed to model the bioactive properties of the implant using the triplet $\left(D_{o}, d_{g}, \alpha_{g}\right)$ locally updated in an active zone of few microns. Osteoblastic flux was governed by the diffusion coefficient $D_{o}$ that conditioned the random motility of cells due to adhesion sites and porosity of the surface. The haptotactic flux was related to local gradient of structural fraction $\phi_{s}$. The capability of implant surface to modify the balance of $T G F-\beta 1$ was taken into account the cell decay factor $d_{g}$ and the synthesis coefficient $\alpha_{g}$. Although conservative equations (3) and (4) allowed it, effects on chemotaxis and cell proliferation were not directly updated by $\chi_{0}$ and $\alpha_{o}$ respectively, but the chemotactic flux was driven by the local growth factor gradient relied to $\alpha_{g}, d_{g}$ and local porosity $\phi_{f}$. This choice was due to a lack of available data in relevant literature. For the same reason, we were unable to update the local effect of bioactive surface on cell proliferation ( $\alpha_{o}$ in equation (3)), and structural (or mineral) matrix synthesis $\left(\alpha_{s}\right.$ in equation (6)).

We considered the mechanobiological interactions between osteoblasts and the implant by using the scale of cell population and growth factor phase. A multi-scale approach could potentially be relevant. This zone could be modeled at the cell scale with addition of local physico-chemical parameters. However, this approach should involve significant knowledge of surface properties and local cell-substrate interactions. This could be a perspective knowing that implementation of bio-mathematical governing equations at this scale should be challenging.

The relevance of our governing equations was initially evaluated in an in-vivo application, which required a custom-made finite element resolution. This application was a stable PMMA canine implant (Vestermark et al. 2004) whose distribution patterns of periprosthetic tissue were available by histomorphometry. About structural fraction $\phi_{s}$, the computational model showed good results in term of magnitudes and spatial distribution. This allowed establishing the basis of a numerical sensitivity analysis where the role of three type of bioactive surface was evaluated: acid-etched titanium, coarse grit blasted acid-etched titanium, and coarse grit blasted acid-etched titanium with $R G D S$ peptide.

The numerical model could have shown numerical instabilities because of strong non-linear coupling. Previously, this risk has been evaluated by implementing a parametric sensitivity analysis (Ambard et al. 2004). Despite large variations of input parameters, up to $\pm 75 \%$, no instability was detected. The modeling of the active zone involving the cell motility, the coefficient of growth factor synthesis and the cellular decay, modified the diffusive terms and the reactive terms of governing equations. This could potentially provoke instabilities. After 
multiple calculations, we checked that no instability of the numerical scheme was induced by these significant perturbations.

The decrease of cell diffusion, acid-etched $+R G D S$ peptide vs $P M M A$, and the increase of growth factor synthesis, $P M M A$ vs acid-etched $+R G D S$ peptide, significantly improved the amount of structural fraction $\phi_{s}$ (or mineralized tissue) on the implant surface. Lower $D_{o}$ induced a longer stay of osteoblasts on the implant surface and higher $\alpha_{g}$ increased concentration of TGF- $\beta 1$. In consequence, osteoblast attraction by chemotaxis was enhanced and mineralized tissue formation was increased.

When the variation pattern of $\phi_{s}$ to doublet $\left(D_{o}, \alpha_{g}\right)$ was investigated, an envelope pattern involving an optimum seemed to be obtained (point $A$ and $B$ in Figure 3). However, when this optimum was exceeded especially for increased value of growth factor synthesis, we obtained a decrease of mineral fraction formation in the active zone. This could be explained by an untimely amount of cells and an early haptotactic migration towards the surrounding bone where the porosity gradient remained high. This result was corroborated by the literature regarding osseoinduction of surface modified substrate, and suggesting that osseointegration could not be optimal for strong surface modification and/or high dose of growth factors (Svehla et al., 2000; Broderick et al. 2005; Buser et al., 2007; Colnot et al., 2007; Qu et al., 2007).

We found that the distribution pattern of new-formed mineralized tissue was not significantly modified in the zones of post-operative gap and host trabecular bone. It confirmed that implant surface properties should play a limited role to reduce heterogeneity of new-formed tissue, which is unfavourable to the long-term survival of the arthroplasty. Our theoretical model involved a significant interest to help in the understanding of complex events in implant fixation. It involved a certain potential to enhance mixed technical-clinical strategy to reduce revision, avoiding empirical strategy. However, the robustness of a predictive model is strongly dependant upon the reliability of input data and because our model relied on interdisciplinary fields, its range of uncertainties was enlarged. Before targeting transfers in clinical setting, we aim at implementing a systems biology approach by which biological questions will be addressed through integrating in-vitro experiments with functionalized bioactive substrates in iterative cycles with computational modelling and theory.

Acknoledgement: J.E. Bechtold PhD and Prof. K. Søballe MD PhD.

\section{References}

Albrektsson, T., Brånemark, P.I., Hansson, H.A., Kasemo, B., Larsson, K., Lundström, I., McQueen, D.H., Skalak, R., 1983. The interface zone of inorganic implants in vivo: Titanium implants in bone. Annals of Biomedical Engineering 11, 1-27.

Alliston, T.N., Derynck, R., 2000. Transforming growth factor- $\beta$ in skeletal development and maintenance. In: Canalis, E. (Ed.), Skeletal Growth Factors. TPA, Philadelphia, 233-249.

Ambard, D., Pedrono, A, Swider, P., 2004. A predictive numerical model of the periprosthetic tissue formation surrounding a stable implant, $50^{\text {th }}$ Annual Meeting of Orthopaedic Research Society, USA.

Ambard, D., Bechtold J.E., Søballe, K., Swider, P. 2004. Prediction of the periprosthetic tissue mineralization in a stable implant coupling cell diffusion in a porous media, 6th Intl Symposium on Computer Methods in Biomechanics and Biomedical Engineering, Spain.

Ambard, D., Bechtold J.E., Søballe, K., Swider, P., 2004. Prediction of the periprosthetic tissue mineralization in a stable implant coupling cell diffusion in a porous media. $6^{\text {th }}$ Intl Symposium on Computer Methods in Biomechanics and Biomedical Engineering. 
Ambard D. 2005. Contribution à l'étude des interactions mécano-biologiques dans la cicatrisation des tissues périprothétiques. $\mathrm{PhD}$ dissertation, University Toulouse 3, France.

Ambard, D., Le Lez, S., Pédrono, A., Swider, P. 2005. Un modèle de prévision de cicatrisation de l'interface os-implant. ITBM-RBM 26, 2, 117-126.

Ambard, D., Swider, P., 2006. A predictive mechano-biological model of the bone-implant healing. European Journal of Mechanics / A Solids 25, 927-937.

Ambard, D., Swider, P.,2007. Volume Strain Effect on Periprosthetic Healing. $53^{\text {th }}$ Annual Meeting of Orthopaedic Research Society, USA.

Ambard, D., Guérin, G., Swider, P., 2009. A reactive poroelastic model to predict the periprosthetic tissue healing. European Journal of Computational Mechanics, 18, 1, 131143.

Anderson, J.M., 2001. Biological responses to materials. Annual Review of Materials Research 31, 81-110.

Anselme, K., 2000. Osteoblast adhesion on biomaterials. Biomaterials 21, 667-681.

Bailón-Plaza, A., Van der Meulen, M.C., 2001. A mathematical framework to study the effects of growth factor influences on fracture healing. Journal of Theoretical Biology 212, 191-209.

Broderick, E., Infanger, S., Turner, T.M., Sumner, D.R., 2005. Depressed bone mineralization following high dose TGF- $\beta 1$ application in an orthopedic implant model. Calcified Tissue International 76, 379-384.

Buser, D., Schenk, R.K., Steinemann, S., Fiorellini, J.P., Fox, C.H., Stich, H., 1991. Influence of surface characteristics on bone integration of titanium implants. A histomorphometric study in miniature pigs. Journal of Biomededical Materials Research 25, 889-902.

Buser, D., Broggini, N., Wieland, M., Schenk, R.K., Denzer, A.J., Cochran, D.L., Hoffmann, B., Lussi, A., Steinemann, S.G., 2004. Enhanced Bone Apposition to a Chemically Modified SLA Titanium Surface. Journal of Dental Research 83, 529-533.

Centrella, M., Horowitz, M.C., Wozney, J.M., McCarthy, T.L., 1994. Transforming growth factor- $\beta$ gene family members and bone. Endocrine Reviews 15, 27-39.

Checa, S., Prendergast, P.J., 2009. A mechanobiological model for tissue differentiation that includes angiogenesis: a lattice-based modeling approach. Annals of Biomedical Engineering 37, 1, 129-145.

Colnot, C., Romero, D.M., Huang, S., Rahman, J., Currey, J.A., Nanci, A., Brunski, J.B., Helms, J.A., 2007. Molecular analysis of healing at a bone-implant interface. Journal of Dental Research 86, 862-867.

Cowin, S.C., 2001. Bone mechanics handbook (second edition). CRC Press, USA.

Dee, K.C., Anderson, T.T., Bizios, R., 1999. Osteoblast population migration characteristics on substrates modified with immobilized adhesive peptides. Biomaterials 20, 221-227.

Duyck, J., Slaets, E., Sasaguri, K., Vandamme, K., Naert, I., 2007. Effect of intermittent loading and surface roughness on peri-implant bone formation in a bone chamber model. Journal of Clinical Periodontology 34, 998-1006.

Fermor, B., Gundle, R., Evans, M., Emerton, M., Pocock, A., Murray, D., 1998. Primary human osteoblast proliferation and prostaglandin $\mathrm{E}_{2}$ release in response to mechanical strain in vitro. Bone 22, 637-643.

Fernandes, P.R., Folgado, J., Jacobs, C., Pellegrini, V., 2002. A contact model with ingrowth control for bone remodelling around cementless stems. Journal of Biomechanics 35, 167 176.

Geris, L., Vandamme, K., Naert, I., Vander Sloten, J., Duick, J., Van Oosterwyck, H., 2008. Application of mechanoregulatory models to simulate peri-implant tissue formation in an in vivo bone chamber. Journal of Biomechanics 41, 145-154.

Geris, L., Gerisch, A., Sloten, J.V., Weiner, R., Oosterwyck, H., 2008. 
Angiogenesis in bone fracture healing: a bioregulatory model.J Theor Biol.; 251(1):13758. Epub 2007 Nov 19.

Grzesik, W.J., Robey, P.G., 1994. Bone matrix RGD glycoproteins: immunolocalization and interaction with human primary osteoblastic bone cells in vitro. Journal of Bone and Mineral Research 9, 487-496.

Kieswetter, K., Schwartz, Z., Hummert, T.W., Cochran, D.L., Simpson, J., Dean, D.D., Boyan, B.D., 1996. Surface roughness modulates the local production of growth factors and cytokines by osteoblast-like MG-63 cells. Journal of Biomedical Materials Research 32, 55-63.

Kilpadi, K.L., Chang, P.L., Bellis, S.L., 2001. Hydroxylapatite binds more serum proteins, purified integrins, and osteoblast precursor cells than titanium or steel. Journal of Biomedical Materials Research 57, 258-267.

Kim, M.J., Kim, C.W., Lim, Y.J., Heo, S.J., 2006. Microrough titanium surface affects biologic response in MG63 osteoblast-like cells. Journal of Biomedical Materials Research Part A 79, 1023-1032.

Lauffenburger, D., Rothman, C., Zigmond, S.H., 1983. Measurement of leukocyte and chemotaxis parameters with a linear under-agarose migration assay. Journal of Immunology 131, 940-947.

Marinucci, L., Balloni, S., Becchetti, E., Belcastro, S., Guerra, M., Calvitti, M., Lilli, C., Calvi, E.M., Locci, P., 2007. Effect of titanium surface roughness on human osteoblast proliferation and gene expression in vitro. International Journal of Oral \& Maxillofacial Implants 21, 719-725. Erratum in: International Journal of Oral \& Maxillofacial Implants $22,19$.

Martin, J.Y., Schwartz, Z., Hummert, T.W., Schraub, D.M., Simpson, J., Lankford, J.Jr, Dean, D.D., Cochran, D.L., Boyan, B.D., 1995. Effect of titanium surface roughness on proliferation, differentiation, and protein synthesis of human osteoblast-like cells (MG63). Journal of Biomedical Materials Research 29, 389-401.

Maheshwari, G., Lauffenburger D.A. 1998. Deconstructing (and reconstructing) cell migration. Microsc res Tech. 43(5):358-68

Maxwell, J.C., 1881. A treatise on electricity and magnetism, $2^{\text {nd }}$ Edn. Claredon Press, Oxford.

Meinel, L., Zoidis, E., Zapf, J., Hassa, P., Hottiger, M.O., Auer, J.A., Schneider, R., Gander, B., Luginbuehl, V., Bettschart-Wolfisberger, R., Illi, O.E., Merkle, H.P., von Rechenberg, B., 2003. Localized insulin-like growth factors I delivery to enhance new bone formation. Bone 33(4), 660-672.

Meirelles, L., Arvidsson, A., Albrektsson, T., Wennerberg, A., 2007. Increased bone formation to unstable nano rough titanium implants. Clinical Oral Implants Research 18, 326-332.

Mesfar, W., Shirazi-Adl, A., Dammak, M., 2003. Modeling of biomedical interfaces with nonlinear friction properties. Biomed Mater Eng.13(1):91-101.

Mustafa, K., Wennerberg, A., Wroblewski, J., Hultenby, K., Lopez, B.S., Arvidson, K., 2001. Determining optimal surface roughness of $\mathrm{TiO}(2)$ blasted titanium implant material for attachment, proliferation and differentiation of cells derived from human mandibular alveolar bone. Clinical Oral Implants Research 12, 515-525.

Neale, G.H., Nader, W.K., 1973. Prediction of transport processes within porous media: Diffusive flow processes within an homogeneous swarm of spherical particles. American Institute of Chemical Engineers Journal 19, 112-119.

Neidlinger-Wilke, C., Wilke, H.J., Claes, L., 1994. Cyclic stretching of human osteoblasts affects proliferation and metabolism: a new experimental method and its application. Journal of Orthopaedic Research 12, 70-78. 
Overgaard, S., 2000. Calcium phosphate coatings for fixation of bone implants. Acta Orthopaedica Scandinavian 71 (Suppl. 297).

Pessková, V., Kubies, D., Hulejová, H., Himmlová, L., 2007. The influence of implant surface properties on cell adhesion and proliferation. Journal of Materials Science: Materials in Medicine 18, 465-473.

Popat, K.C., Leoni, L., Grimes, C.A., Desai, T.A., 2007. Influence of engineered titania nanotubular surfaces on bone cells. Biomaterials 28, 3188-3197.

Prendergast, P.J., 1997. Finite element models in tissue mechanics and orthopaedic implant design. Clinical Biomechanics 12, 343-366.

Puthumanapully P., New A., Browne M., 2008. Do multi-layer beads on porous coated implants influence bone ingrowth? A finite element study. Journal of Biomechanics 41, S290.

Qu, Z., Rausch-Fan, X., Wieland, M., Matejka, M., Schedle, A., 2007. The initial attachment and subsequent behavior regulation of osteoblasts by dental implant surface modification. Journal of Biomededical Materials Research A 82, 658-668.

Ramamurti, B.S., Orr, T.E., Bragdon, C.R., Lowenstein, J.D., Jasty, M., Harris, W.H. 1997. Factors influencing stability at the interface between a porous surface and cancellous bone: a finite element analysis of a canine in vivo micromotion experiment. J Biomed Mater Res. 36(2):274-80.

Rausch-fan, X., Qu, Z., Wieland, M., Matejka, M., Schedle, A., 2008. Differentiation and cytokine synthesis of human alveolar osteoblasts compared to osteoblast-like cells (MG63) in response to titanium surfaces. Dental Materials 24, 102-110.

Roberts, A.B., 2000. Transforming growth factor- $\beta$. In: Canalis, E. (Ed.), Skeletal Growth Factors. TPA, Philadelphia, 221-232.

Rosa, A.L., Beloti, M.M., 2003. Rat bone marrow cell response to titanium and titanium alloy with different surface roughness. Clinical Oral Implants Research 14, 43-48.

Schwartz, Z., Kieswetter, K., Dean, D.D., Boyan, B.D., 1997. Underlying mechanisms at the bone-surface interface during regeneration. Journal of Periodontal Research 32, 166-171.

Schwarz, F., Herten, M., Sager, M., Wieland, M., Dard, M., Becker, J., 2007. Histological and immunohistochemical analysis of initial and early osseous integration at chemically modified and conventional SLA titanium implants: preliminary results of a pilot study in dogs. Clinical Oral Implants Research 18, 481-488.

Simon, U., Augat, P., Ignatius, A., Claes, L. 2003. Influence of the stiffness of bone defect implants on the mechanical conditions at the interface; a finite element analysis with contact. J Biomech. 36(8):1079-86.

Sims and Baron, 2000. Bone cells and their function. In: Canalis, E. (Ed.), Skeletal Growth Factors. TPA, Philadelphia, 1-16.

Sinha, R.K., Tuan, R.S., 1996. Regulation of human osteoblast integrin expression by orthopaedic implant materials. Bone 18, 451-457.

Søballe K., Hansen E.S., B-Rasmussen H., Jorgensen P.H., Bunger C. 1992. Tissue ingrowth into titanium and hydroxyapatite-coated implants during stable and unstable mechanical conditions. J Orthop Res. Mar. 10(2): 285-99.

Stein, G.S., Owen, T.A., van Wijnen, A.J., Cho, B., Stein, J.L., Lian, J.B., 2000. Mechanisms of action of skeletal Growth factors in osteoblasts. In: Canalis, E. (Ed.), Skeletal Growth Factors. TPA, Philadelphia, 51-65.

Svehla, M., Morberg, P., Zicat, B., Bruce, W., Sonnabend, D., Walsh, W.R., 2000. Morphometric and mechanical evaluation of titanium implant integration: Comparison of five surface structures. Journal of Biomededical Materials Research 51, 15-22.

Vestermark M.T., Bechtold J.E., Swider P., Søballe K. 2004. Mechanical interface conditions affect morphology and cellular activity of sclerotic bone rims forming around 
experimental loaded implants. J Orthop Res. 22(3): 647-52.

Viceconti, M., Muccini, R., Bernakiewicz, M., Baleani, M., Cristofolini, L.2000. Largesliding contact elements accurately predict levels of bone-implant micromotion relevant to osseointegration. J Biomech. 33(12):1611-8.

Wakefield, L.M., Winokur, T.S., Hollands, R.S., Christopherson, K., Levinson, A.D., Sporn, M.B., 1990. Recombinant latent transforming growth factor $\beta 1$ has a longer plasma halflife in rats than active transforming growth factor $\beta 1$, and a different tissue distribution. Journal of Clinical Investigation 86, 1976-1984.

Wang, J.Y., Wicklund, B.H., Gustilo, R.B., Tsukayama, D.T., 1997. Prosthetic metals interfere with the functions of human osteoblast cells in vitro. Clinical Orthopaedics and Related Research 339, 216-226.

Wu, C.Y., Fields, A.J., Kapteijn, B.A.E., McDonald, J.A., 1995. The role of a4b1 integrin in cell motility and fibronectin matrix assembly. Journal of Cell Science 108, 821-829. 


\section{Captions for Tables and Illustrations}

Table 1 - Parameters of the reference computational model (PMMA implant). Data were from relevant litterature: Wakefield et al.1990; Maheshwari et al. 1998; Dee et al. 1999; Tranqui et al. 2000; Vestermark et al, 2004; Bailon-Plaza et al 2001; Raush-fan et al. 2008.

Table 2 - Bioactive properties of active zone according to four type of substrate. Values were computed from equation (7a) and (7b) using data from relevant literature: Wakefield et al.1990; Raush-fan et al. 2008. Coefficients for other tissue were $\alpha_{g}=5 \times 10^{-12} \mathrm{ng} / \mathrm{cell} \mathrm{s}$ and $D_{o}=2.5 \times 10^{-7} \mathrm{~mm}^{2} / \mathrm{s}$.

Figure 1 - (a) The periprosthetic zone of interest comprises three sub-domains: the host trabecular bone, the post-operative gap and the active zone of few microns thick where implant bioactive properties modified growth factor sources and cell flux. (b) Canine experimental device: stable PMMA implant. (c) Axisymetric model of the canine implant device showing the radial location of zones of interest: host trabecular bone, post-operative gap, implant active zone.

Figure 2 - Radial distribution patterns of structural fraction $\phi_{s}$ for different types of implants. The experimental pattern concerned the PMMA implant and it was obtained from histomorphometry. The active zone of 15 microns thick was located at the implant surface and sensitivity analysis involved titanium substrate with three types of bioactive surface treatment: acid-etched, coarse-grit-blasted acid-etched, coarse-grit-blasted acid-etched with $R G D S$ peptide. 
Parameters

\begin{tabular}{lll}
\hline Geometry & $r_{i}=3.25 \mathrm{~mm} r_{s}=7 \mathrm{~mm}$ & $r_{d}=4.1 \mathrm{~mm}$ active zone $: 15 \mu \mathrm{m}$ \\
\hline \multirow{4}{*}{ Osteoblast } & $C_{o}=1000 \mathrm{cell} / \mathrm{mm}^{3}$ & $h_{o}=1.8 \times 10^{-6} \mathrm{~mm}^{5} / \mathrm{s} . \mathrm{kg}$ \\
& $C_{o m}=10000 \mathrm{cell} / \mathrm{mm}^{3}$ & $\chi_{o}=3 \times 10^{-5} \mathrm{~mm}^{5} / \mathrm{s} . n g$ \\
& $\alpha_{o}=1.9 \times 10^{-10} \mathrm{~mm}^{6} /$ cell.ng.s & $D_{o}=2.5 \times 10^{-7} \mathrm{~mm}^{2} / \mathrm{s}$ \\
& $\alpha_{s}=6 \times 10^{-9} \mathrm{~mm}^{6} /$ cell ng s & \\
\hline \multirow{2}{*}{ Growth factor } & $C_{g}=0.15 \mathrm{ng} / \mathrm{mm}^{3} C_{g p}=0.05 \mathrm{ng} / \mathrm{mm}^{3}$ & $\alpha_{g}=5 \times 10^{-12} \mathrm{ng} / \mathrm{cell} \mathrm{s}$ \\
& $D_{g}=4.8 \times 10^{-6} \mathrm{~mm}^{2} / \mathrm{s}$ & $d_{g}=8.5 \times 10^{-11} \mathrm{~mm}^{3} / \mathrm{cell} \mathrm{s}$ \\
\hline
\end{tabular}

Table 1 - Parameters of the reference computational model (PMMA implant). Data were from relevant litterature: Wakefield et al.1990; Maheshwari et al. 1998; Dee et al. 1999; Tranqui et al. 2000; Vestermark et al, 2004; Bailon-Plaza et al 2001; Raush-fan et al. 2008.

active zone of implant

\begin{tabular}{ccccc}
\hline & PMMA & $\begin{array}{c}\text { acid-etched } \\
\text { titanium }\end{array}$ & $\begin{array}{c}\text { coarse grit } \\
\text { blasted } \\
\text { acid-etched } \\
\text { titanium } \\
+R G D S \text { peptide }\end{array}$ \\
$d_{g}\left(10^{-11} \mathrm{~mm}^{3} /\right.$ cell s) & 8.5 & 8.5 & 8.5 & 8.5 \\
$\alpha_{g}\left(10^{-12} \mathrm{ng}^{-\mathrm{cell} \mathrm{s})}\right.$ & 5 & 8.5 & 21 & 21 \\
$D_{o}\left(10^{-7} \mathrm{~mm}^{2} / \mathrm{s}\right)$ & 2 & 1.6 & 1.6 & 1.45 \\
\hline
\end{tabular}

Table 2 - Bioactive properties of active zone according to four type of substrate. Values were computed from equation (7a) and (7b) using data from relevant literature: Wakefield et al.1990; Raush-fan et al. 2008. Coefficients for other tissue were $\alpha_{g}=5 \times 10^{-12} \mathrm{ng} / \mathrm{cell} \mathrm{s}$ and $D_{o}=2.5 \times 10^{-7} \mathrm{~mm}^{2} / \mathrm{s}$. 

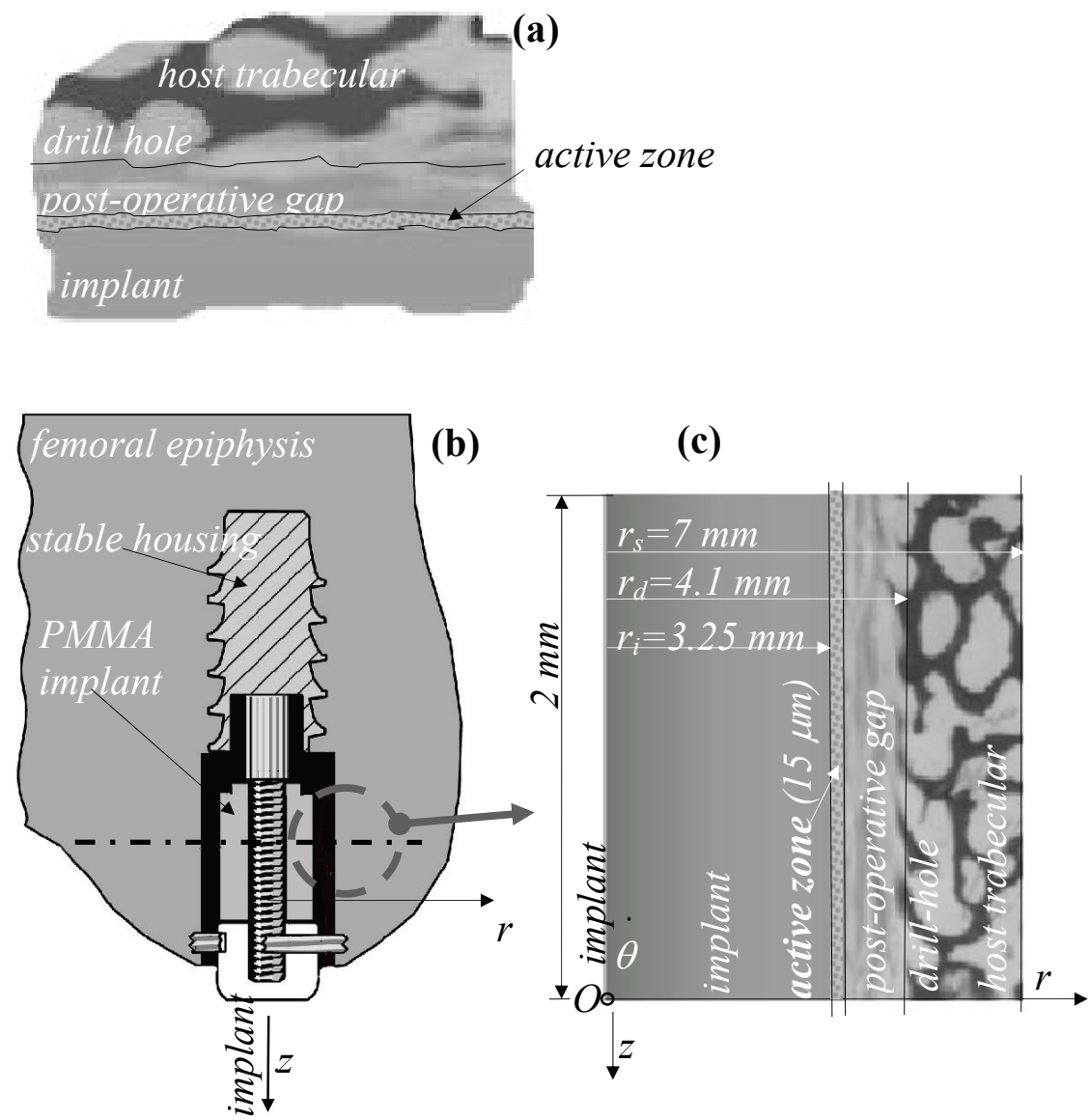

Figure 1 - (a) The periprosthetic zone of interest comprises three sub-domains: the host trabecular bone, the post-operative gap and the active zone of few microns thick where implant bioactive properties modified growth factor sources and cell flux. (b) Canine experimental device: stable $P M M A$ implant. (c) Axisymetric model of the canine implant device showing the radial location of zones of interest: host trabecular bone, post-operative gap, implant active zone. 
Mechanobiology and implant surface properties

Guérin G., Ambard D., Swider P.

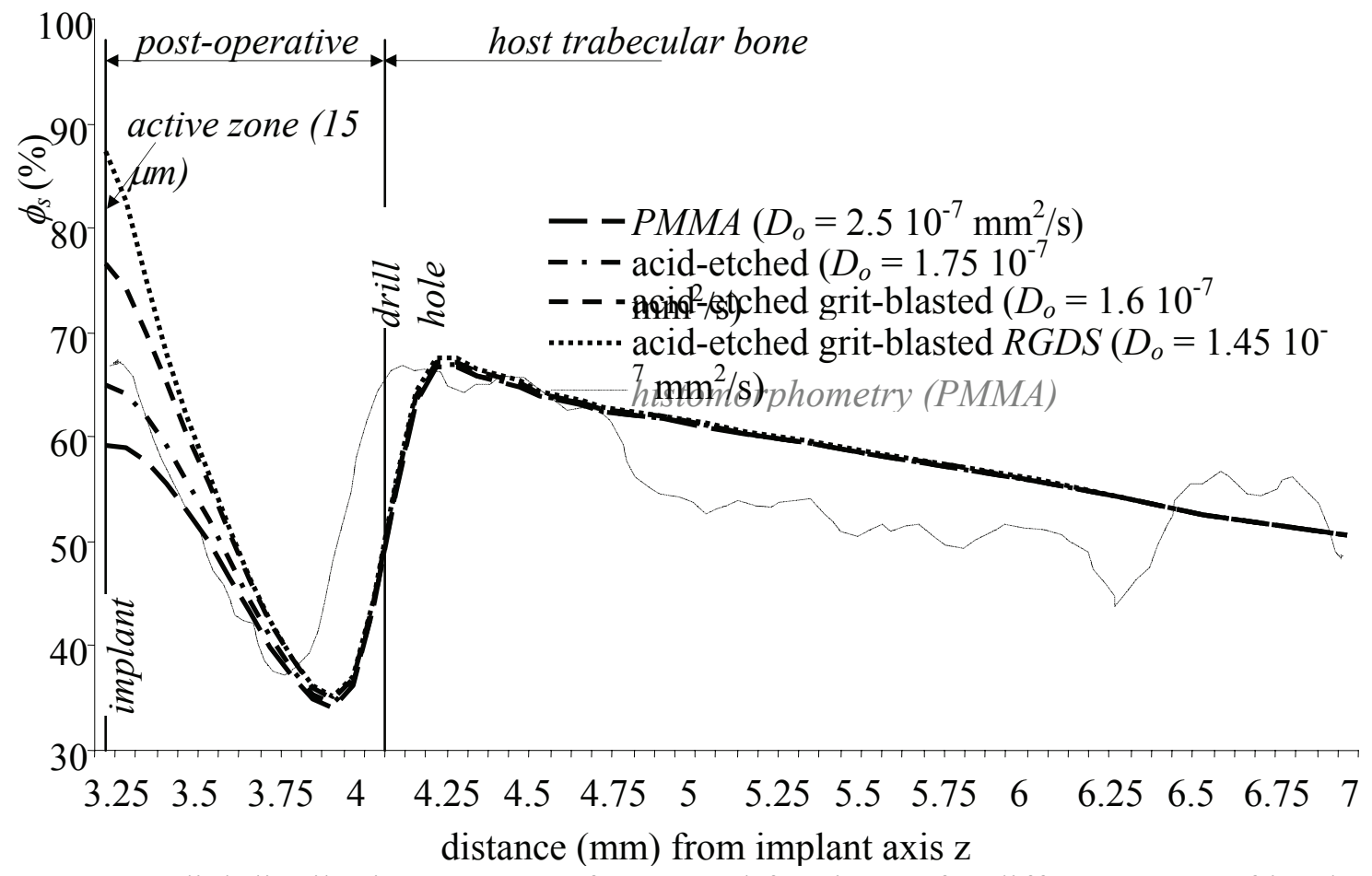

Figure 2 - Radial distribution patterns of structural fraction $\phi_{s}$ for different types of implants. The experimental pattern concerned the $P M M A$ implant and it was obtained from histomorphometry. The active zone of 15 microns thick was located at the implant surface and sensitivity analysis involved titanium substrate with three types of bioactive surface treatment: acid-etched, coarse-grit-blasted acid-etched, coarse-grit-blasted acid-etched with $R G D S$ peptide. 
Mechanobiology and implant surface properties

Guérin G., Ambard D., Swider P.

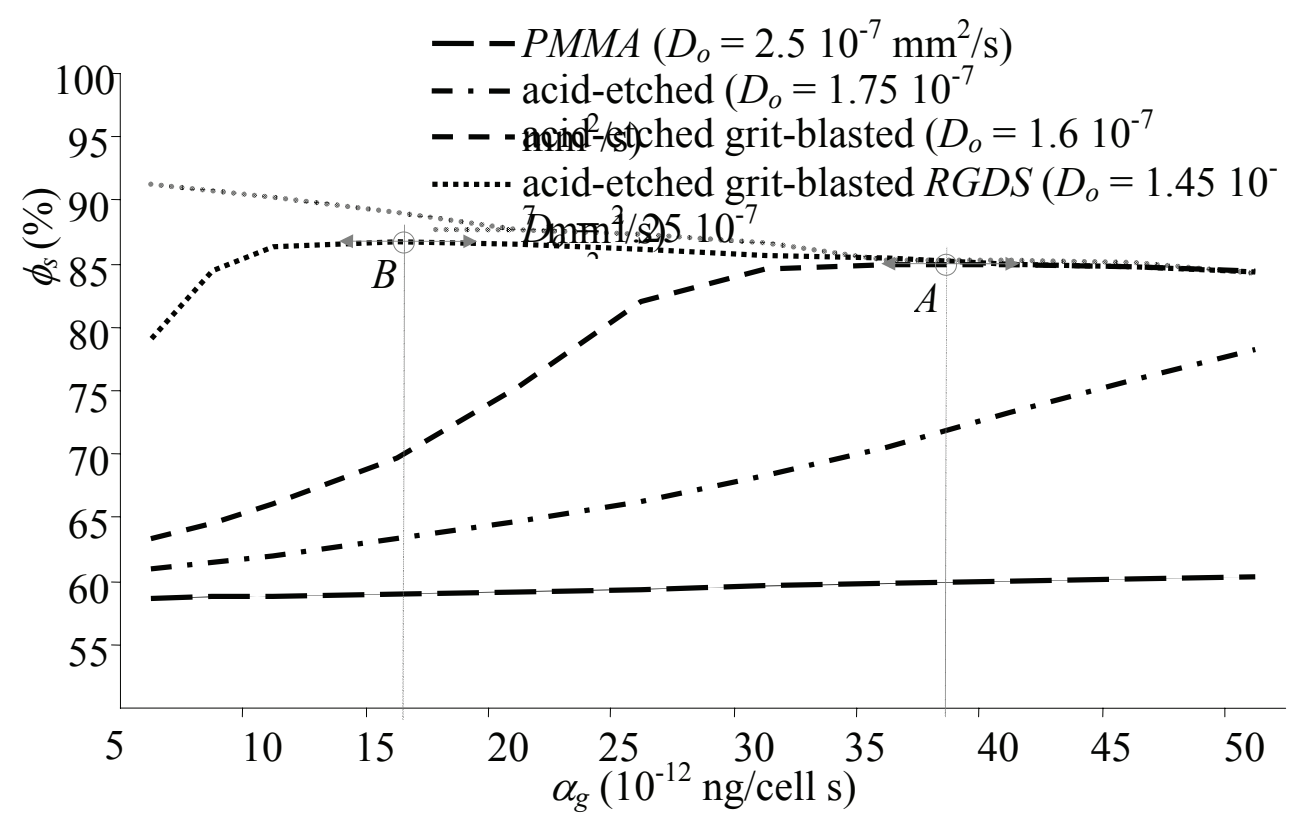

Figure 3 - Influence of bioactive surface treatment on the structural fraction $\phi_{s}$ in the active zone located at the implant surface. Surface dependant parameters were the diffusion coefficient $D_{o}\left(10^{-7} \mathrm{~mm}^{2} / \mathrm{s}\right)$ and the coefficient of growth factor production in autocrine mode $\alpha_{g}\left(10^{-12} \mathrm{ng} /\right.$ cell s $)$. The cell decay factor was constant $\left(d_{g}=8.5 \times 10^{-11} \mathrm{~mm}^{3} /\right.$ cell s $)$. Materials were $P M M A$ and titanium substrate with three types of bioactive surface treatment: acidetched, coarse-grit-blasted acid-etched, coarse-grit-blasted acid-etched with $R G D S$ peptide. 